\title{
A PRACTICAL RELIABILITY-BASED CAPACITY RATING OF EXISTING ROAD BRIDGES
}

\author{
By Jae-Chul SHIN*, Hyo-Nam CHO** and Dong-Il CHANG***
}

\begin{abstract}
This study is directed for the evolution of rational approaches to the systematic evaluation of the load carrying capacity of bridges based on the practical and advanced second moment reliability methods. Raliability-based rating criteria in the form of load and resistance factor rating (LRFR) code are presented in order to show the direction of the development of rating codes. Furthermore, an approach using the reliability index as a measure of rating of an existing bridge is suggested.

Keywords: bridge rating, load carrying capacity rating, code calibration, reliability methods, load and resistance factor rating
\end{abstract}

\section{INTRODUCTION}

In most countries road bridges are subjected to increasingly heavy freight traffic with a number of exceptional truck loads. This has made it necessary to devote particular attention to the evaluation of safety and load-carrying capacity of bridges, which is a vital process in the decision-making for maintenance, repair, strengthening, or even replacement of existing road bridges. However, most countries including Korea do not have a comprehensive rating system or rating code. Furthermore, the current methods of rating of road bridges are dependent on the conventional design concepts and the safety parameters of the current bridge design codes. In spite of the fact that the rating of existing bridges unlike the design situations requires a careful and detailed evaluation of many complex factors and conditions, many countries still use working stress methods for rating calculations. Of course, more and more countries are in the process of turning to adopting limit state methods.

Recent advances in structural code development are primarily directed toward probability-based framework of limit state design or load and resistance factor design ${ }^{1)}{ }^{4)}$. However, little attention has been paid to the development of probability-based bridge rating methods or rating codes. Recently, Ghosn and Moses $^{5)}$ among others proposed a practical reliability method for the analysis, rating, or design of road bridges based on the practical load model derived with the measured load spectra obtained with the WIM (Weigh-In-Motion) technique. Also, Schelling and $\mathrm{Fu}^{6)}$ proposed a generalized rating methods and compared the ratings with three alternate methods; i. e., the Working Stress Rating (WSR), Load Factor Rating (LFR), and Auto-Stress Rating (ASR). Schelling and Fu argued that the use of LFR or

* Associate Professor, Chungnam National Univ., Chungnam, Korea

** Professor, Hanyang Univ., Seoul, Korea

*** Professor, Hanyang Univ., Seoul, Korea 
ASR methods is best ensured with the presence of the added load capacity.

One of the main objectives of this paper is to propose a reliability-based bridge rating criteria in the form of Load and Resistance Factor Rating (LRFR) code which can be developed by incorporating the actual bridge conditions into the limit state models such as the "measured-to-calculated" load effects, the composite actions, deteriorations, and damages based on field inspection, measurement or test data. The reliability-based rating criteria are derived based on the practical and advanced second moment reliability methods ${ }^{7) .8)}$. The scope of this paper will be limited to the safety against the strength limit states of short span road bridges because some of the critical serviceability limit states such as fatigue warrant separate treatment.

\section{PROBABILITY-BASED BRIDGE RATING MODEL}

\section{(1) Limit state model}

A limit state failure function in terms of the output variables of resistance and load effects may be stated as in the following linear form ${ }^{7) .9)}$;

$R-\left(S_{D}+S_{L}\right) \leq 0$

where, $\quad R=$ resistance random variable

$S_{D}, S_{L}=$ dead and live load effect random variables, respectively

Both resistance and load effects of Eq. (1) for bridge rating have to be modeled in a slightly different form from those for the design criteria as may be shown in the following.

The element resistance model of a strength failure mode for an existing bridge incorporating the uncertainties of deterioration of the bridge under consideration may be given as follows;

$$
R=R_{n} M F P D
$$

where, $R_{n}=$ nominal strength resistance of real section considering deterioration, corrosion or damage, etc.

$M=$ random variable representing material strength uncertainties

$F=$ random variable characterizing fabrication or construction uncertainties

$P=$ random variable indicating the uncertainties of prediction or modelling

$D=$ random variable incorporating the uncertainties involved in the assessments of damages and/or deteriorations

Since the dead load and the truck load are responsible for the governing loads of a short span bridge, the load effects $S_{D}, S_{L}$ reflecting field inspection or test results may be expressed, respectively, as follows ;

$$
S_{D}=C_{D} D_{n} D_{s} L_{D}
$$

where, $C_{D}=$ deterministic influence coefficient for dead load effect of the unit dead load

$D_{n}=$ nominal dead load

$D_{S}=$ random variable reflecting the uncertainties involved in the transformation of $D_{n}$ into $S_{D}$

$L_{D}=$ random variable representing dead load uncertainties

$$
S_{L}=C_{L} P_{n} K^{\prime} P_{S} P_{T} L_{P}
$$

where, $C_{L}=$ deterministic influence coefficient for live load effects corresponding to the unit live load

$P_{n}=$ nominal truck load (standard rating or standard design trucks)

$K^{\prime}=K_{s}^{\prime} K_{i}^{\prime}(1+I)$

in which $K_{s}^{\prime}=$ the ratio of the measured stress to the calculated stress

$K_{i}^{\prime}=$ the ratio of the measured impact factor $\left(1+i_{t}\right)$ to the calculated impact factor $\left(1+i_{c}\right)$ :

$$
\left[\left(1+i_{t}\right) /\left(1+i_{c}\right)\right]
$$

$I=$ nominal impact factor

$P_{S}=$ random variable reflecting the uncertainties involved in the transformation of $P_{n}$ into $S_{L}$ (load distribution, analysis and modelling uncertainties)

$P_{T}=$ random variable related with the uncertainties involved in the process of measurement or 
testing (static or dynamic test results such as measured stress, deflections, or impact) $L_{P}=$ random variable of random traffic loads (deviation of heavy traffic loads from rating vehicle)

\section{(2) Rating model}

The load and resistance factor rating (LRFR) criteria corresponding to the widely accepted LRFD criteria would rather be considered as a natural choice than WSR or LFR for rational rating code. A LRFR code can be calibrated by following the well established procedure for the design code calibrations ${ }^{1) .2(9)}$. In the paper, the safety parameters $\phi^{\prime}, \gamma_{i}^{\prime}$ of limit states of a bridge type for a given load ratio are determined by a computer code which incorporates AFOSM (Advanced First Order Second Moment) procedure together with the equivalent normal transformation ${ }^{10)}$. The outlines of the AFOSM structural reliability methods used in this paper are well illustrated in the references ${ }^{7), 8), 11) \sim 13)}$.

At the minimum distance point of limit state failure surfaces in the reduced space, Eq. (1) becomes $R^{*}-S_{D}^{*}-S_{L}^{*}=0$

Notice that the means of the variables, $R, S_{D}, S_{L}$ may be expressed as

$$
\begin{aligned}
& \bar{R}=R_{n} \bar{M} \bar{F} \bar{P} \bar{D}=R_{n} \eta_{R} \\
& \bar{S}_{D}=C_{D} D_{n} \bar{D}_{S} \bar{L}_{D}=C_{D} D_{n} \eta_{D} \\
& \bar{S}_{L}=C_{L} P_{n} K^{\prime} \bar{P}_{T} \bar{P}_{S} \bar{L}_{P}=C_{L} P_{n} K^{\prime} \eta_{L}
\end{aligned}
$$

and also notice that in terms of the safety parameters $\phi, \gamma_{i}, R^{*}, S_{D}^{*}, S_{L}^{*}$ may be given, by definition, as follows ;

$$
\begin{aligned}
& R^{*}=\phi \bar{R} \\
& S_{D}^{*}=\gamma_{D} \bar{S}_{D} \\
& S_{L}^{*}=\gamma_{L} \bar{S}_{L}
\end{aligned}
$$

Then, the limit state equation, Eq. (5), becomes

$$
\phi \eta_{R} R_{n}-\gamma_{D} \eta_{D} C_{D} D_{n}-\gamma_{L} \eta_{L} C_{L} K^{\prime} P_{n}=0
$$

Therefore, from Eq. ( 8 ), the nominal load carrying capacity, $P_{n}$, of an existing bridge may be obtained as follows ;

$$
P_{n}=\frac{\phi^{\prime} R_{n}-\gamma_{D}^{\prime} C_{D} D_{n}}{\gamma_{L}^{\prime} C_{L} K^{\prime}}
$$

where, $\phi^{\prime}=\phi \eta_{R}$ (nominal resistance factor)

$\gamma_{D}^{\prime}=\gamma_{D} \eta_{D}$ (nominal dead load factor)

$\gamma_{L}^{\prime}=\gamma_{L} \eta_{L}$ (nominal live load factor)

\section{STATISTICAL UNCERTAINTIES}

The assessment of statistical uncertainties of basic random variables of resistance and load effects is

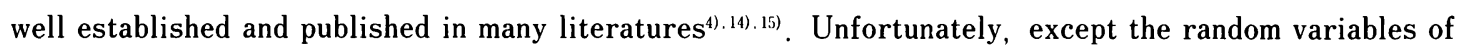
material strength or loads, the uncertainties of most random variables with regard to resistance and load effects have to be estimated based on the judgement and experiences due to the inherent nature of uncertainties and/or the lack of the data available. Thus, uncertainties of random variables described herein are estimated and obtained mainly from the data available in the literatures or partly from the engineering judgements.

\section{(1) Uncertainties of resistance}

The uncertainties of resistances may be obtained from the linear approximation technique, and resistances are assumed to be log-normally distributed. The first two statistical moments of each basic variable are determined from the available data; however, based on judgement $\bar{D}$ and $V_{D}$ are tentatively assumed to be $\bar{D}=1.0, V_{D}=0.1$ in this paper. The results of these uncertainties are summarized in 
Table 1 Statistical Uncertainties of Resistance.

\begin{tabular}{|l|c|c|c|c|c|c|c|c|}
\cline { 2 - 9 } \multicolumn{1}{c|}{} & \multicolumn{2}{c|}{ R. C Beam } & \multicolumn{2}{c|}{ R. C. S1ab } & \multicolumn{2}{c|}{ I Beam } & \multicolumn{2}{c|}{ Plate Girder } \\
\cline { 2 - 9 } & $\bar{R} / R_{\mathbf{n}}$ & $V_{R_{0}}$ & $\bar{R} / R_{\mathbf{n}}$ & $V_{R_{0}}$ & $\bar{R} / R_{\mathbf{n}}$ & $V_{R_{0}}$ & $\bar{R} / R_{\mathbf{n}}$ & $V_{R_{0}}$ \\
\hline $\begin{array}{l}\text { E11ingwood } \\
1982\end{array}$ & 1.14 & 0.14 & 1.12 & 0.16 & 1.07 & 0.13 & 1.08 & 0.12 \\
\hline This paper & 1.12 & 0.16 & 1.20 & 0.16 & 1.07 & 0.15 & 1.08 & 0.15 \\
\hline
\end{tabular}

Table 2 Statistical Uncertainties of Dead Load Effects.

\begin{tabular}{|cc|cc|c|c|}
\hline$\overline{\mathrm{D}}_{\mathrm{S}}$ & $\mathrm{V}_{\mathrm{DS}}$ & $\overline{\mathrm{L}}_{\mathrm{D}}$ & $\mathrm{V}_{\mathrm{L}_{\mathrm{D}}}$ & $\overline{\mathrm{S}}_{\mathrm{D}} / \mathrm{S}_{\mathrm{D}_{\mathbf{D}}}$ & $\mathrm{V}_{\mathrm{S}_{\mathrm{D}}}$ \\
\hline 1.0 & 0.05 & 1.05 & 0.08 & 1.05 & 0.10 \\
\hline
\end{tabular}

Table 3 Statistical Uncertainties of Live Load Effects.

\begin{tabular}{|l|cc|cc|cc|c|c|}
\cline { 2 - 8 } \multicolumn{1}{l|}{} & $\overline{\mathrm{P}}_{\mathrm{S}}$ & $\mathrm{V}_{\mathrm{PS}_{\mathrm{S}}}$ & $\overline{\mathrm{P}}_{\mathrm{T}}$ & $\mathrm{V}_{\mathrm{P}_{\mathrm{T}}}$ & $\overline{\mathrm{L}}_{\mathrm{P}}$ & $\mathrm{V}_{\mathbf{L}_{\mathrm{P}}}$ & $\overline{\mathrm{S}}_{\mathrm{L}} / \mathrm{S}_{\mathrm{L}_{\mathrm{n}}}$ & $\mathrm{V}_{\mathrm{S}_{\mathrm{L}}}$ \\
\hline $\begin{array}{l}\text { R.C. T Beam } \\
\text { R.C. Slab } \\
\text { I Beam }\end{array}$ & 1.0 & 0.10 & 1.0 & 0.05 & 1.24 & 0.22 & 1.24 & 0.25 \\
\hline Plate Girder & 1.0 & 0.10 & 1.0 & 0.05 & 1.15 & 0.16 & 1.15 & 0.19 \\
\hline
\end{tabular}

Table 1. Note that the coefficient of variation given in Table 1 is $V_{R 0}=\sqrt{V_{M}^{2}+V_{F}^{2}+V_{P}^{2}}$, which is, in turn, to be used for $V_{R}=\sqrt{V_{R 0}^{2}+V_{D}^{2}}$. This means $V_{D}$ is treated separately.

\section{(2) Uncertainties of load effects}

The random variables which should be accounted for in a load model include the number of trucks, their gross weight, axle spacings and axle weight distribution and the relative positions of these trucks with respect to one another ${ }^{(6)} \sim 18$. The live load uncertainties in this paper are drawn from the model developed by Ghosn and Moses ${ }^{5}$, because no stochastic load models are available so far in Korea, although research on the traffic load model is in process. And the uncertainties of other basic variables of dead and live load effects are estimated based on the engineering judgement, from the available data of the previous study ${ }^{19}$, or by referring to the Nowak ${ }^{20)}$ and Moses $^{5)}$. Again, the uncertainties of each load effects are calculated by using the linear approximation technique, and dead load and live load effects are assumed to be normally and log-normally distributed, respectively. They are summarized as in Table 2 and 3, respectively.

\section{SAFETY ASSESSMENT OF EXISTING BRIDGES}

A rating method using the reliability index $(\beta)$ as a means of rating is suggested in order to evaluate the load carrying capacity of deteriorated bridges. Based on the results of field inspections or measurements, the nominal resistance in consideration of the degrees of deterioration or damage and the nominal load effects incorporating all the correction factors obtained from the measured-to-calculated responses are analyzed in a conventional way. Then, the calculation of safety index $(\beta)$ may be performed by using either by MFOSM-based log-log model formula ${ }^{5)}$ or AFOSM-based computer code developed for this study.

The following tentative rule as shown in Table 4 may be suggested as a guide to evaluate the load carrying capacity of deteriorated bridges.

If a computer code for a practical evaluation of the systems reliability $\beta_{s}$ is available, $\beta_{s}$ could replace the element reliability, $\beta_{e}$. For the purpose of bridge rating, a 2nd order bound estimate or a point estimate based on an approximate formulation is preferred rather than a theoretical formulation using Monte Carlo simulation based on a complete nonlinear analysis ${ }^{201.211}$. 
Table 4 Capacity Rating and Recommended Maintenance Policy.

\begin{tabular}{|c|l|}
\hline $\begin{array}{c}\beta \geq \beta_{0} \\
\left(\hat{\beta}_{0}=3.0\right)\end{array}$ & $\begin{array}{l}\text { Capacity : Normal (Safe) } \\
\text { Maintenance : Regular visual inspection }\end{array}$ \\
\hline $2.0 \leq \beta<\beta_{0}$ & $\begin{array}{l}\text { Capacity } \quad \text { Limited (SLR \& MOR to be evaluated) } \\
\text { Maintenance : Repair and weight limit to be posted }\end{array}$ \\
\hline $1.0 \leq \beta<2.0$ & $\begin{array}{l}\text { Capacity } \quad \text { Seriously limited (SLR \& MOR to be } \\
\text { evaluated) } \\
\text { Maintenance } \\
\text { to be posted }\end{array}$ \\
\hline$\beta<1.0$ & $\begin{array}{l}\text { Capacity : Completely lost } \\
\text { Maintenance }: \text { Retrofitting or replacement }\end{array}$ \\
\hline
\end{tabular}

\section{BRIDGE RATING CODE CALIBRATION}

To achieve desired levels of consistent reliability, the code calibration procedure for optimally selecting code parameter values of load and resistance variables based on target reliability levels for limit states is well established and documented in several procedure reports such as CEB ${ }^{1)}$, CIRIA report $63^{2)}$ and NBS SP-577).

(1) Selection of target reliability index

The most important single step in the calibration of a code is the selection of a rational target reliability index for each limit state. Various approaches for selecting a set of target reliability indices were suggested in the aforementioned reports. Unfortunately, detailed systematic results based on this approach are not available so far; and, thus, in consideration of implicit differences between system level reliabilities and element reliabilities, the following target reliability indices for flexural strength limit states are tentatively used in this paper, identical to the widely accepted value for flexural strength limit states ;

- $\beta_{0}=3.0$ : Service Load Rating (SLR)

- $\beta_{0}=2.0:$ Max. Overload Rating (MOR)

(2) Sensitivity of safety parameters

To verify the characteristics of the safety parameters before calibration, the sensitivity of $\phi, \gamma_{i}$ to the variation of the load ratio is investigated for each different type of bridges as shown in Fig. 1 and 2.

Observed in Fig. 1 is that $\phi$ and $\gamma_{D}$ take almost constant values for the variation of load ratio, $P_{n} / D_{n}$ while $\gamma_{L}$, as expected, is quite sensitive because the uncertainties of live load, $V_{L}$, is relatively larger than those of dead load and resistance, $V_{D}, V_{R}$. Numerically, Fig. 1 shows that, for the variation of load ratio, $P_{n} / D_{n}$, from 0.5 to $3.0, \phi$ increases about 0.07 , whereas $\gamma_{D}$ decreases about 0.06 but $\gamma_{L}$ increases about

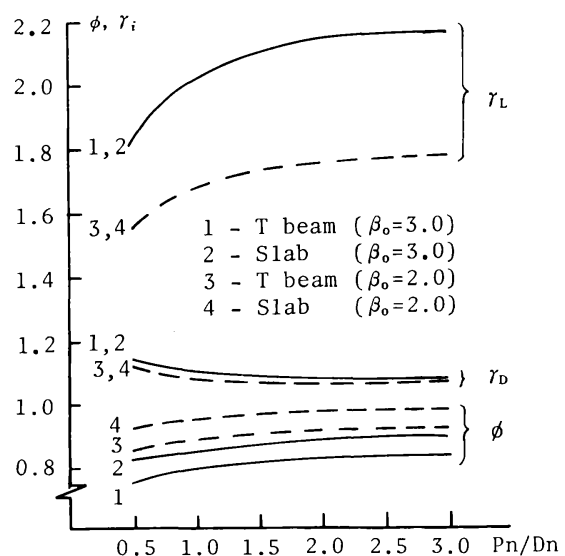

Fig. $1 P_{n} / D_{n}$ v. s. $\phi, \gamma_{i}$ (R. C. Bridge).

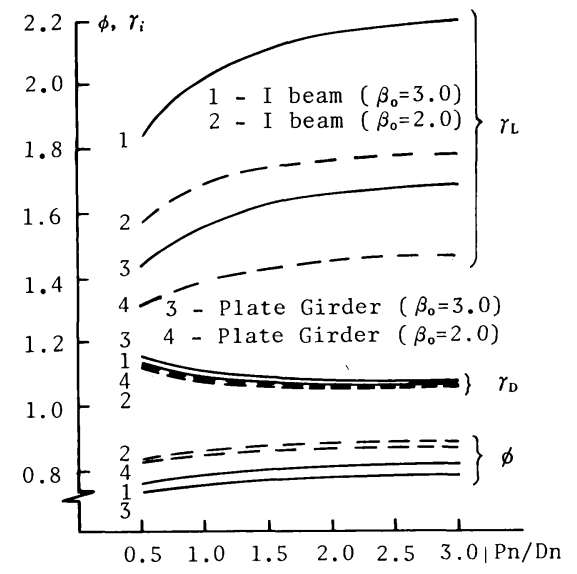

Fig. $2 P_{n} / D_{n}$ v.s. $\phi, \gamma_{i}$ (Steel Bridge). 
0.35. Similar results may be observed in the case of steel bridges as shown in Fig. 2.

\section{(3) Calibration of safety parameters}

The LRFR criteria described in this paper is calibrated by a practical method so that the reliabilities are nearly uniform for all load situations as well as for each bridge type considered. In order to achieve a consistent level of safety near the target reliability index using the level-I LRFR code, the resistance factor, $\phi^{\prime}$, of each bridge type and the common load factors, $\gamma_{i}^{\prime}$, respectively, for service load and overload ratings are apportioned by the following calibration procedure. First, the common load factor, $\gamma_{D}^{\prime}, \gamma_{L}^{\prime}$, may be determined by minimizing the weighted squared difference between the required level- II characteristic resistance, $R_{c}^{\Pi}$, computed from level-II AFOSM algorithm corresponding to $\beta_{0}$ and the required level- I characteristic resistance $R_{c}^{l}$, in terms of load factors of level- I code format defined by

$$
I\left(\gamma_{D}^{\prime}, \gamma_{L}^{\prime}\right)=\sum_{i} \sum_{j} p_{i} q_{j}\left(R_{c i j}^{I}-R_{c i j}^{\prime}\right)^{2}
$$

where $p_{i}=$ relative weight assigned to each bridge type considering the relative frequency of the bridge $q_{j}=$ relative weight assigned to each load ratio $\left(P_{n} / D_{n}\right)_{j}$

Note that the minimization technique used in this paper is somewhat different from the technique used by Ellingwood ${ }^{9}$. The common load factor, $\gamma_{D}^{\prime}, \gamma_{L}^{\prime}$, may also be determined approximately from the minimization of $I\left(\gamma^{\prime}\right)$ considering the relative weight of bridge type by using the most probable load ratio for each bridge.

Once the common load factors are determined, the resistance factor $\phi^{\prime}$ for each bridge type may be calculated, similarly, by minimizing $I\left(\phi^{\prime}\right)$ which is expressed in terms of nominal resistances

$I\left(\phi^{\prime}\right)=\sum_{j} q_{s}\left(R_{n}^{I}-R_{n}^{I}\right)^{2}$

Table 5 shows the results of the average $\phi, \gamma_{i}$ corresponding to the most probable load ratio for each bridge type, which is calculated from the computer code that comprises the AFOSM procedure.

Based on the results of calibration, the proposed load and resistance factors are summarized as in Table 6 and 7, in which $\phi$ values are selected as round-up values by considering the efficiency in practical applications. Also, it has to be noted that the dead load factor, $\gamma_{D}^{\prime}=1.2$ is selected by considering the global acceptance of 1.2 as desirable value, and the corresponding $\gamma_{L}^{\prime}$ is determined from the minimization of Eq. (10).

It is interesting to observe that the load factors of the proposed LRFR in Table 6 is significantly different from those of AASHTO $^{22)}$ especially in case of live load factors.

Next, in order to check the consistency of reliability of the proposed LRFR code provisions according to the variation of load ratio, the reliability indices are plotted for each type of bridge as shown in Fig. 3. Here, the reliabilities are almost constant to the variation of load ratio. Thus, it is to be noted that except for plate girder bridges, selected reliability levels are a little bit higher than the target reliability index because the factors are adjusted as mentioned above.

Based on the results of calibration of the proposed LRFR code, the tentative provisions may be presented as in Table 8.

Table $5 \phi, \gamma_{i}$ for Each Bridge Type.

\begin{tabular}{|l|c|c|c|c|c|c|c|c|}
\hline \multirow{2}{*}{ Bridge } & \multirow{2}{*}{$\begin{array}{l}\text { Re1ative } \\
\text { frequency }\end{array}$} & \multirow{2}{*}{\begin{tabular}{l} 
ratio \\
\cline { 4 - 8 }
\end{tabular}} & \multicolumn{3}{|c|}{$\beta_{\mathrm{o}}=3.0$} & \multicolumn{3}{|c|}{$\beta_{\mathrm{o}}=2.0$} \\
\hline $\begin{array}{c}\text { R.C. } \\
\text { T Beam }\end{array}$ & 0.4 & 1.0 & 0.790 & 1.097 & 2.021 & 0.880 & 1.086 & 1.677 \\
\hline $\begin{array}{l}\text { Cont. } \\
\text { R.C Slab }\end{array}$ & 0.15 & 2.0 & 0.878 & 1.074 & 2.134 & 0.966 & 1.069 & 1.750 \\
\hline I Beam & 0.3 & 2.0 & 0.806 & 1.075 & 2.167 & 0.880 & 1.070 & 1.768 \\
\hline $\begin{array}{c}\text { Plate } \\
\text { Girder }\end{array}$ & 0.15 & 0.5 & 0.728 & 1.151 & 1.427 & 0.828 & 1.121 & 1.312 \\
\hline
\end{tabular}

These proposed LRFR provisions can preferably be used for the rating of existing bridges, although they are not derived from the precise statistical uncertainty data. However, incorporating more improved statistical data, they can be updated or modified if necessary. Therefore the proposed LRFR could possibly replace the current rating formula which is based on the conventional WSR. Of cours, note 
Table 6 The Proposed Common Load Factor.

\begin{tabular}{|l|c|c|}
\cline { 2 - 3 } \multicolumn{1}{c|}{} & $r_{\mathbf{D}}^{\prime}$ & $r_{\mathbf{L}}^{\prime}$ \\
\hline Service Load & $1.2(1.3)$ & $2.4(2.17)$ \\
\hline Max. Overload & $1.2(1.3)$ & $2.0(1.3)$ \\
\hline
\end{tabular}

* ( ) : factors of AASHTO rating provisions

Table 7 The Proposed Resistance Factor.

\begin{tabular}{|c|l|c|c|}
\cline { 2 - 4 } \multicolumn{2}{c|}{} & Service Load & Max. Overload \\
\hline \multirow{2}{*}{ R. C. } & T Beam & 0.85 & 0.95 \\
\cline { 2 - 4 } & Cont. S1ab & 0.95 & 1.0 \\
\hline \multirow{2}{*}{ Stee1 } & I Beam & 0.80 & 0.90 \\
\cline { 2 - 4 } & Plate Girder & 0.90 & 1.0 \\
\hline
\end{tabular}

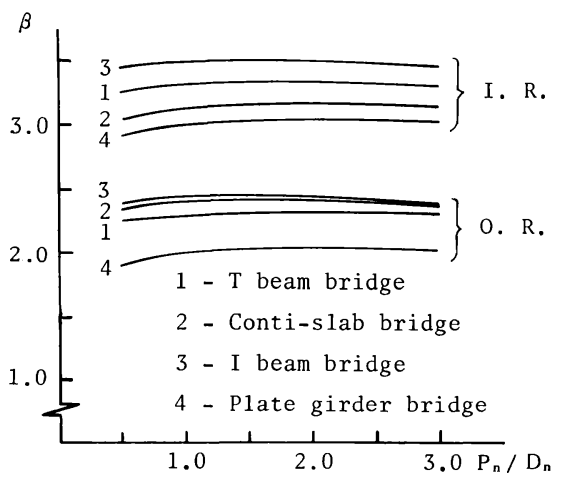

Fig. 3 Load ratio v. s. $\beta$ corresponding to the proposed $\phi, \gamma_{i}$.

Table 8 The Proposed Rating Provisions.

\begin{tabular}{|l|c|c|}
\cline { 2 - 3 } \multicolumn{1}{c|}{} & \multicolumn{2}{|c|}{$\mathrm{P}_{\mathrm{n}}=\frac{\phi^{\prime} R_{\mathrm{n}}-\gamma_{\mathrm{D}}^{\prime} \mathrm{C}_{\mathrm{D}} \mathrm{D}_{\mathrm{n}}}{\gamma_{\mathrm{L}}^{\prime} \mathrm{C}_{\mathrm{L}} \mathrm{K}^{\prime}}$} \\
\cline { 2 - 3 } R.C. T Beam & $\frac{0.85 \mathrm{R}_{\mathrm{n}}-1.2 \mathrm{C}_{\mathrm{D}} \mathrm{D}_{\mathrm{n}}}{2.4 \mathrm{~K}^{\prime} \mathrm{C}_{\mathrm{L}}}$ & $\frac{0.95 \mathrm{R}_{\mathrm{n}}-1.2 \mathrm{C}_{\mathrm{D}} \mathrm{D}_{\mathrm{n}}}{2.0 \mathrm{~K}^{\prime} \mathrm{C}_{\mathrm{L}}}$ \\
\hline R.C Slab & $\frac{0.95 \mathrm{R}_{\mathrm{n}}-1.2 \mathrm{C}_{\mathrm{D}} \mathrm{D}_{\mathrm{n}}}{2.4 \mathrm{~K}^{\prime} \mathrm{C}_{\mathrm{L}}}$ & $\frac{1.0 \mathrm{R}_{\mathrm{n}}-1.2 \mathrm{C}_{\mathrm{D}} \mathrm{D}_{\mathrm{n}}}{2.0 \mathrm{~K}^{\prime} \mathrm{C}_{\mathrm{L}}}$ \\
\hline I Beam & $\frac{0.80 \mathrm{R}_{\mathrm{n}}-1.2 \mathrm{C}_{\mathrm{D}} \mathrm{D}_{\mathrm{n}}}{2.4 \mathrm{~K}^{\prime} \mathrm{C}_{\mathrm{L}}}$ & $\frac{0.90 \mathrm{R}_{\mathrm{n}}-1.2 \mathrm{C}_{\mathrm{D}} \mathrm{D}_{\mathrm{n}}}{2.0 \mathrm{~K}^{\prime} \mathrm{C}_{\mathrm{L}}}$ \\
\hline Plate Girder & $\frac{0.90 \mathrm{R}_{\mathrm{n}}-1.2 \mathrm{C}_{\mathrm{D}} \mathrm{D}_{\mathrm{n}}}{2.4 \mathrm{~K}^{\prime} \mathrm{C}_{\mathrm{L}}}$ & $\frac{1.0 \mathrm{R}_{\mathrm{n}}-1.2 \mathrm{C}_{\mathrm{D}} \mathrm{D}_{\mathrm{n}}}{2.0 \mathrm{~K}^{\prime} \mathrm{C}_{\mathrm{L}}}$ \\
\hline
\end{tabular}

that WSR can still be used if the safety factors of the WSR code are calibrated by using the same probabilistic procedure presented in this paper.

\section{APPLICATIONS AND DISCUSSIONS}

So far, each year a number of investigations about the load carrying capacity of deteriorated existing bridges in Korea have been made with conventional rating methods by the National Construction Research Institute ${ }^{23)}$ and the Korea Highway Co. ${ }^{24)}$. However, in this paper reliabilities and ratings of some of these bridges are evaluated in terms of the proposed LRFR criteria in close comparison with the reported results. Also, comparative study on the rating methods of other countries is also made by using the rating example shown in the OECD report ${ }^{25)}$.

(1) Reliability evaluation of deteriorated bridges

Although due to the page limit the data of field surveys of several deteriorated example bridges extracted from the reports of $\mathrm{NCRI}^{23)}$ and $\mathrm{KHWC}^{24)}$ are not presented, results of the reliability assessments of these bridges based on the proposed model and AFOSM algorithm are shown in Table 9. Observing the calculated reliability index for each bridge, the proposed tentative guide agrees fairly well with the evaluation of the maintenance policy described in the reports.

Therefore, the results of reliability evaluations of the example bridges indicate that the reliability index $\beta$ may be used as a preliminary means of rating existing bridges with only visual inspections. 
A comparison of the results rated by using the DB-standard truck of the KSCE bridge design code between the proposed LRFR rating code (Table 8) and the conventional rating formula of the reports is summarized as in Table 10.

It may be observed that there are significant differences between the results of proposed LRFR and those of the conventional WSR. Considering that the current WSR rating formula could result in rather irrational ratings because of inherent shortcomings in the conventional WSR which is not reliability based, the results of the proposed LRFR can be regarded as more rational ratings.

(2) Comparison with rating methods of other countries

Many countries still use working stress methods for rating calculations, but the countries which use limit state methods are drastically increasing in number nowadays. In order to investigate how various rating systems affect the rating factor and consequently the load permitted on the bridge, the example of rating calculation for a typical noncomposite steel beam bridge of span length $21 \mathrm{~m}$ is taken from the OECD report $^{25}$. The rating vehicle was the U.S. 3S2 unit (72 kips). For comparison, nominal resistance and load effects as those in the U.S. rating method were used, except that the factor $K^{\prime}$, which is the ratio of the measured to calculated load effects is taken in two different way; $K^{\prime}=1.0$ (for no consideration) and $K^{\prime}=0.8$ (those average typical value for steel beam bridges). Results of the calculations are summarized as in Table 11.

As shown in Table 11, considerable differences result in allowable service loads or maximum loads which are permitted on the same bridge rated by the same vehicle configuration due to the differences of rating methods or codes used by four countries (Korea, USA, UK, Canada). In more detail, the variations in allowable loads come out because of differences in lateral load distribution calculations, different impact factors and the different opinion about the continuing undamaged operation of the bridge.

Table 9 Results of Reliability Evaluation of Example Bridges.

\begin{tabular}{|c|c|c|c|}
\hline Bridge & Type & $\beta$ & Evaluation \\
\hline Jackchun & $\mathrm{T}$ Beam & 2.61 & . Bridge is in good condition \\
\hline Sanyang & $\mathrm{T}$ Beam & 1.26 & $\begin{array}{l}\text { - Weight limit to be posted } \\
\text { - Detailed rating to be evaluated } \\
\text { - Repair and rehabilitation to be } \\
\text { planned }\end{array}$ \\
\hline Nongong & $\begin{array}{l}\text { Cont. } \\
\text { Slab }\end{array}$ & 1.12 & $\begin{array}{l}\text { - Bridge is in dangerous condition } \\
\text { - Detailed rating to be evaluated } \\
\text { - Repair and rehabilitation to be plan- } \\
\text { ned }\end{array}$ \\
\hline Danpo & I Beam & 0.71 & $\begin{array}{l}\text { - Bridge is in extremely dangerous } \\
\text { condition } \\
\text { - Closing or replacement to be planned } \\
\text {. Extensive field measurements needed }\end{array}$ \\
\hline Nakdong & $\begin{array}{l}\text { Plate } \\
\text { Girder }\end{array}$ & 1.59 & $\begin{array}{l}\text { - Weight limit to be posted } \\
\text { - Detailed rating to be evaluated } \\
\text { - Repair and rehabilitation to be } \\
\text { planned }\end{array}$ \\
\hline
\end{tabular}

Table 10 Comparison of Results $\left(P_{n}\right)$ of Ratings.

\begin{tabular}{|l|c|c|c|}
\hline \multirow{2}{*}{ Bridge } & \multicolumn{2}{|c|}{ LRFR } & WSR \\
\cline { 2 - 4 } & $\begin{array}{c}\text { Service } \\
\text { Load } \\
\text { Rating }\end{array}$ & $\begin{array}{l}\text { Max. } \\
\text { Overload } \\
\text { Rating }\end{array}$ & $\begin{array}{l}\text { Service Load } \\
\text { Rating }\end{array}$ \\
\hline Jakchun & 5.54 & 8.22 & 12.67 \\
\hline Sanyang & 4.32 & 6.71 & 5.707 \\
\hline Nongong & 8.93 & 11.50 & 6.01 \\
\hline Danpo & 3.44 & 5.04 & 4.60 \\
\hline Nakdong & 7.26 & 12.26 & 13.99 \\
\hline
\end{tabular}

${ }^{*} P_{n}=$ rated by the DB-standard truck load 
Table 11 Rating Factors.

\begin{tabular}{|c|c|c|c|c|c|c|}
\hline & \multirow{2}{*}{ Canada } & \multirow{2}{*}{\multicolumn{2}{|c|}{\begin{tabular}{|l|l|} 
United & United \\
Kingdom & States \\
\end{tabular}}} & \multicolumn{2}{|c|}{ This Study (LRFR) } \\
\hline & & & & & $K^{\prime}=1.0$ & $K^{\prime}=0.8$ \\
\hline CSA & $\begin{array}{l}\text { Design } \\
\text { Situation } \\
\text { Unsupervised } \\
\text { supervised }\end{array}$ & $\begin{array}{l}1.046 \\
1.533 \\
3.255\end{array}$ & - & - & - & - \\
\hline $\begin{array}{l}\text { Service } \\
\text { Load }\end{array}$ & $\begin{array}{l}\text { WSR } \\
\text { LFR }\end{array}$ & - & $\begin{array}{c}1.110 \\
-\end{array}$ & $\begin{array}{l}1.427 \\
1.537\end{array}$ & $-\overline{1.180}$ & $\overline{1.475}$ \\
\hline $\begin{array}{l}\text { Max. } \\
\text { Overload }\end{array}$ & $\begin{array}{l}\text { WSR } \\
\text { LFR }\end{array}$ & - & $\begin{array}{c}3.980 \\
-\end{array}$ & $\begin{array}{l}2.329 \\
2.562\end{array}$ & 1.680 & 2.100 \\
\hline
\end{tabular}

* CSA $=$ Canadian Standards Association
The meaningful comparison may be made between the $\mathrm{AASHTO}^{22}$ rating and the proposed LRFR because the method of nominal calculation are identical except for the safety and rating parameters. As it is shown in Table 11, ratings by the proposed LRFR result in lower values which is conservative side values compared with the $\mathrm{AASHTO}^{22)}$ ratings. This is mainly due to the consideration of all the statistical uncertainties included in the model of the

proposed LRFR. It is also to be noted that a considerable discrepancy in the results exists even between $K^{\prime}$ $=1.0$ (without consideration of real responses of the bridge) and $K^{\prime}=0.8$ (with consideration of average real responses of the bridge).

Thus, all the conventional rating methods of the three other countries can not effectively predict the realistic load carrying capacity of a deteriorated bridge because they do not explicitly account for the effects of measurements and the degrees of the deterioration in the rating calculations. From the above observation, it can be asserted that, to predict the real load carrying capacity of an existing bridge, the rating method should consider the effects of actual response and the degrees of deterioration based on bridge field inspection and measurements. Furthermore, all the uncertainties involved in the variables of loads and resistances should be properly taken into consideration in a form of reliability based LRFR criteria.

\section{CONCLUDING REMARKS}

This paper has described reliability based safety assessment and bridge rating of existing bridges, and proposed a rating method in a form of LRFR code provisions by considering all the uncertainties of loads and resistances based on the AFOSM reliability method, and also by accounting for the effects of actual responses of a bridge with field measurements and degrees of deterioration. Based on the observation and results of the applications the following conclusions are made;

(1) The reliability index as a measure of safety level or rating of an existing bridge may be effectively used in performing bridge ratings and decision makings for further maintenance action.

(2) The proposed LRFR criteria have more rational bases than the conventional WSR or LFR criteria because all the statistical uncertainties are systematically included, and effects of the actual responses and deterioration of bridges are explicitly accounted for.

(3) Since there exists inherent rationality in a reliability based rating method, the current rating formula based on the WSR method should be replaced by the proposed LRFR code provisions, once more elaborate and realistic statistical data are available in the near future.

\section{REFERENCES}

1) CEB (Comité Europeen du Béton) : Common Unified Rules for Different Types of Construction and Material, CEB Bulletin No. 116 E, 1976.

2) CIRIA (Construction Industry Research and Information Association) : Rationalisation of Safety and Serviceability Factors in Structural Code, CIRIA Report No.63, London, 1977.

3) JSCE : Standard Specification for Concrete : Design Part, Japan Society of Civil Engineers, 1986.

4) NBS (National Bureau of Standards) : Development of a Probability Based Load Criterion for American National Standard A 58, Ed. by Ellingwood, B. et al., SP-577, June 1980.

5) Ghosn, M. and Moses, F. : Bridge Load Modelling and Reliability Analysis, RR 84-1, Dept. of Civil Eng., Western Reserve Univ., May 1984. 
6) Schelling, D. R. and Fu, C. C. : Comparison of Bridge Rating Methods, Jour. of Structural Eng., ASCE, Vol. 110, No. 7, pp. 1447 1466, July 1984.

7) Ang, A. H-S. and Tang, W. H. : Probability Concepts in Engineering Planning and Design, Vol. II, John Wiley \& Sons, Inc., 1984.

8) Madsen, H. O. et al. : Method of Structural Safety, Prentice-Hall, Inc., Englewood Cliffs, 1986.

9) Ellingwood, B. et al. : Probability Based Load Criteria : Load Factors and Load Combinations, Jour. of Structural Div., ASCE, Vol. 108, No. ST 5, pp. 978 997, May 1982.

10) Rackwitz, R. and Fiessler, B. : Structural Reliability under Combined Random Load Sequences, Computers \& Structures, Vol.9, pp. 489 494, 1978.

11) Shiraishi, N., Furuta, H. and Nakano, M. : Some Considerations on Application of Safety Index to Reliability Analysis, Proc. of JSCE, No. 301, pp. 13 22, Sept. 1980.

12) Shiraishi, N., Furuta, H. and Nakano, M. : Some Considerations on Structural Design Based on Second-Moment Theory, Proc. of JSCE, No.311, pp.1 12, July 1981.

13) Sugiyama, T., Sakai, T., Fujino, Y. and Ito, M. : Decisions on Reliability Level and Safety Factor for Structural Design, Proc. of JSCE, No. 327, pp. 1 28, Nov. 1982.

14) ASCE (American Society of Civil Engineers) : Probabilistic Basis for Design Criteria in Reinforced Concrete, Reinforced Concrete Research Council, ASCE Bulletin No. 22, 1985.

15) Ravindra, M. K. and Galambos, T. V. : Load and Resistance Factor Design for Steel, Jour. of the Structural Div., ASCE, Vol. 104, No. ST 9, pp. 1337 1354, Sept. 1979.

16) Fujino, Y., Ito, M. and Endo, M. : Design Traffic Live Load for Highway Bridges Based on Computer Simulation, Proc. of JSCE, No. 286, pp. 1 13, Jan. 1979.

17) Shinozuka, M., Matsumura, S. and Kubo, M. : Analysis of Highway Bridge Response to Stochastic Live Loads, Proc. of JSCE, No. 344/I-1, pp. 367 376, Apr. 1984.

18) Shiraki, W., Matsuho, S., Yamamoto, K. and Takaoka, N. : Reliability Analysis of a Continuous Two-Span Bridge Girder, Proc. of JSCE, No.368/I-5, pp. 225 233, Apr. 1986.

19) Cho, Hyo-Nam : A Study on Reliability Based Design Criteria for Reinforced Concrete Bridge Superstructures, Proc. of KSCE (Korean Society of Civil Engineers), Vol.2, No.3, pp. 87 99, Sept. 1983.

20) Nowak, H. S. and Zhou, J. : Reliability Models for Bridge Analysis, Research Report, Dept. of Civil Eng., Univ. of Michigan, 1985.

21) Bennett, R. M. and Ang, A. H-S. : Investigation of Methods for Structural System Reliability, Structural Research Series No. 510, Univ. of Illinois, Urbana-Champaign, Illinois, 1983.

22) AASHTO (American Association for State Highway and Transportation Officials) : Manual for Maintenance Inspection of Bridges, 1978.

23) NCRI (National Construction Research Institute) : Evaluation of Load Carrying Capacity of Road Bridges, Research Report No. 499, Dec. 1984.

24) KHWC (Korea Highway Coporation) : Investigation of Structural Performance and Material Integrity of Highway Bridge, Research Report No. 150, Dec. 1985.

25) OECD (Organization for Economic Co-operation and Development) : Evaluation of Load Carrying Capacity of Bridges, A Report Prepared by an OECD Road Research Group, Dec. 1979. 